\title{
EVALUATION OF MICROVASCULAR AND MACROVASCULAR COMPLICATIONS IN TYPE 2 DIABETES MELLITUS
}

\author{
Rajendran Thilakavathi', Parthasarathy Prathiba², Pillanallur Rajendran Saiprashanth ${ }^{3}$, Venkatachalam Vivek ${ }^{4}$
}

${ }^{1}$ Associate Professor, Department of General Medicine, Government Vellore Medical College and Hospital.

${ }^{2}$ Assistant Professor, Department of General Medicine, Government Vellore Medical College and Hospital.

3 Postgraduate Student, Department of General Medicine, Government Vellore Medical College and Hospital.

${ }^{4}$ Postgraduate Student, Department of General Medicine, Government Vellore Medical College and Hospital.

\begin{abstract}
\section{BACKGROUND}

Diabetes Mellitus comprises a group of common metabolic disorder that shares the phenotype of Hyperglycaemia. Several distinct types of DM exist and is caused by complex interaction of genetic, environmental factors and lifestyle choices. The two broad categories of DM are designated as Type 1 and Type 2 Diabetes. Type 1 Diabetes occurs due to autoimmune Beta cell destruction. Type $2 \mathrm{DM}$ is a heterogeneous group of disorder characterised by variable degrees of insulin resistance, impaired insulin secretion and increased glucose production.

The objective of this study is to evaluate the microvascular and macrovascular complications of Type 2 Diabetes Mellitus among patients attending the Diabetology Outpatient Department at Government Vellore Medical College and Hospital, Vellore.
\end{abstract}

\section{MATERIALS AND METHODS}

The present study was a cross-sectional study done on patients with age more than 35 years with type 2 Diabetes Mellitus attending the Diabetology Outpatient Department at Government Vellore Medical College and Hospital for a period of 6 months. Sample Size- The sample size was estimated through convenient sampling method. After satisfying the inclusion criteria, the total number of patients included in the study was 100 . The selected patients underwent detailed clinical and biochemical evaluations. The results were calculated using SPSS V 16 Software and were expressed in percentage.

\section{RESULTS}

The sample size of the study was 100. Maximum patients with diabetes were between 41 - 60 years of age. $70 \%$ of patients had duration of diabetes $<5 \mathrm{yrs}$. Of the total number of patients $72 \%$ were found to be hypertensive, $57 \%$ were found to be obese, $20 \%$ of the study population were smokers and $74 \%$ were found to have hypercholesterolaemia which was found to be the highest risk factor followed by hypertension. The prevalence of retinopathy, neuropathy and nephropathy were 34\%, 20\% and 32\% respectively. The most common microvascular complication was retinopathy. Among the newly diagnosed DM patients, the prevalence of retinopathy, neuropathy and nephropathy were 34\%, 24\% and 24\% respectively. Among the macrovascular complications the prevalence of coronary artery disease, peripheral vascular disease and cerebrovascular disease was found to be $36 \%, 6 \%$ and $10 \%$ respectively. The most common macrovascular complication was CAD.

\section{CONCLUSION}

In this study 53\% of patients were males and 47\% were females, all of them being above 35 years of age. The mean age of the patients was 54 years. The highest number of patients with diabetes was in the age group of $51-60$ years. $70 \%$ of patients had duration of diabetes $<5$ years. Hypertension was found in $72 \%$ of patients.

\section{KEYWORDS}

Diabetes Mellitus, Complications, Nephropathy, Neuropathy, Retinopathy, Vasculopathy.

HOW TO CITE THIS ARTICLE: Thilakavathi R, Prathiba P, Saiprashanth PR, et al. Evaluation of microvascular and macrovascular complications in type 2 diabetes mellitus. J. Evolution Med. Dent. Sci. 2018;7(09):1130-1135, DOI: 10.14260/jemds/2018/257

\section{BACKGROUND}

Diabetes Mellitus comprises a group of common metabolic disorders that shares the phenotype of hyperglycaemia. Several distinct types of DM exist and is caused by complex interaction of genetic, environmental factors and lifestyle choices.

'Financial or Other Competing Interest': None.

Submission 17-01-2018, Peer Review 09-02-2018,

Acceptance 16-02-2018, Published 26-02-2018.

Corresponding Author:

Dr. Parthasarathy Prathiba,

19/24, Ramanathan Street,

T. Nagar,

Chennai-600017.

E-mail: prathusarathy@gmail.com

DOI: $10.14260 /$ jemds $/ 2018 / 257$

\section{(c) $($ ) $\$$}

The Two Broad Categories of DM are designated as Type 1 and Type 2 Diabetes

- Type 1 Diabetes occurs due to auto-immune Beta cell destruction.

- Type 2 DM is a heterogeneous group of disorder characterised by variable degrees of insulin resistance, impaired insulin secretion and increased glucose production.

The chronic complication of DM affects many organ systems and is responsible for the majority of morbidity and mortality associated with the disease. The vascular complication of DM are further subdivided into Microvascular (Retinopathy, Neuropathy, Nephropathy) and Macrovascular (coronary artery disease, peripheral arterial disease and cerebrovascular disease). 
The microvascular complications of both Type 1 and Type 2 DM result from chronic hyperglycaemia. Since Type 2 DM often has a long asymptomatic period of hyperglycaemia, many individuals with type $2 \mathrm{DM}$ have complications at the time of diagnosis.

Evidence implicating a causative role of chronic hyperglycaemia in macrovascular complications is less conclusive. Moreover, coronary heart disease events and mortality are two to four times greater in patients with Type 2 DM. Other factors like dyslipidaemia and hypertension play an important role in macrovascular complications.

\section{Aim of the Study}

(1) To evaluate the microvascular and macrovascular complications of Type 2 Diabetes Mellitus, attending the Diabetology Outpatient Department at Government Vellore Medical College and Hospital, Vellore. The patients were categorised according to the duration of Diabetes for the purpose of study into-
(a) Newly diagnosed DM.
(b) DM of $<5$ years.
(c) DM for 5 - 10 years.
(d) $\mathrm{DM}>10$ years.

(2) To evaluate the risk factors such as hypertension, obesity, hypercholesterolaemia and smoking.

\section{MATERIALS AND METHODS}

\section{Study Design}

The study was a cross-sectional study done on patients with age more than 35 years with type 2 Diabetes Mellitus attending the Diabetology Outpatient Department at Government Vellore Medical College and Hospital for a period of 6 months. The sample size was estimated by convenient sampling method.

\section{Selection of Cases}

Patients with type 2 DM aged more than 35 years attending the Diabetology Outpatient Department at Government Vellore Medical College and Hospital were evaluated for-

A. Risk factors- Hypertension, Obesity, Smoking and Hypercholesterolaemia.

B. Microvascular Complications- Retinopathy, Neuropathy and Nephropathy.

C. Macrovascular Complications- CAD, Cerebrovascular Disease, Peripheral Vascular Disease.

D. For evaluation of complication, they were categorised according to the duration of Diabetes.

1. Newly diagnosed DM.

2. $\mathrm{DM}$ of $<5$ years.

3. DM for $5-10$ years.

4. $\mathrm{DM}>10$ years.

A detailed history was recorded in respect of all the subject patients, particularly the duration of DM, Smoking, Complications, Family History of DM etc.

\section{The following Criteria was taken/ Diagnosis of Diabetes}

- Fasting Plasma Glucose $>126 \mathrm{mg} \%$

- 2 hrs. Plasma Glucose > 200 mg\%

\section{Criteria for Risk Factors \\ Diagnosis of Hypertension 21}

\begin{tabular}{|c|c|c|}
\hline Stages & Systolic & Diastolic \\
\hline Pre-Hypertension & $120-139$ & $80-89$ \\
\hline Hypertension Stage 1 & $140-159$ & $90-99$ \\
\hline Hypertension Stage 2 & $>160$ & $>100$ \\
\hline
\end{tabular}

\section{Obesity}

(a) Body Mass Index= Weight in kgs/Height in (Meter) ${ }^{2}$

- Overweight 25-30

- $\quad$ Obese $>30$

(b) Waist Circumference 22

- $\quad$ Male $>90 \mathrm{~cm}$

- $\quad$ Female $>80 \mathrm{~cm}$

(c) Total Cholesterol 23

- $\quad 200$ Normal.

- 200 - 239 Borderline High.

- $<240$ High.

\section{Criteria for Microvascular Complications}

1. Diabetic Retinopathy: Ocular Fundus examination by ophthalmoscope after dilatation of pupils.

(a) Non-proliferating Diabetic Retinopathy:

- Microaneurysm, Haemorrhage, Hard Exudates

(b) Proliferative Retinopathy:

- New Vessels on Disc (NVD)

- $\quad$ New Vessels Elsewhere (NVE)

(c) Clinically Significant Macular Oedema (CSME):

- Thickening of retina located $500 \mu \mathrm{U} / \mathrm{m}$ from the centre of macula.

- Hard exudates with thickening of adjacent retina located $500 \mu \mathrm{U} / \mathrm{m}$ from the centre of macula.

- Zone of retinal thickening of one disk area or larger in size, located one disc diameter from the centre of macula.

2. Diabetic Nephropathy:

(a) Macroproteinuria- Protein excretion of $>500 \mathrm{mg} /$ day, out of which $50 \%$ is albumin. Macroalbuminuria was tested. Microalbuminuria was not tested.

(b) Serum Creatinine.

- Calculation of GFR done based on Cockroft-Gault Formula. ${ }^{24}$

$$
\begin{aligned}
& \text { Estimated creatinine clearance }(\mathrm{ml} / \mathrm{min})= \\
& (140 \text { - Age }) \text { X body weight }(\mathrm{kg}) \\
& 72 \text { X P Creatinine }(\mathrm{mg} / \mathrm{dL})
\end{aligned}
$$

Multiply by 0.85 for women.

3. Diabetic Neuropathy:

Symptoms of sensory and motor signs on physical examination were done.

\section{Criteria for Macrovascular Complications}

1. Cardiovascular Disease

History: Symptoms of Angina- Chest pain.

ECG:

- LVH.

- Ischaemic Heart Disease- DT - T were checked for changes.

- Features of old MI. 
Echo: (Taken where necessary as follows)

- Diastolic dysfunction in HT.

- Regional wall motion abnormalities.

- Ejection Fraction.

2. Peripheral Vascular Disease.

Clinical examination of peripheral palpable arteries done. Doppler study was done in relevant cases.

3. Stroke.

- History and Clinical examination for stroke was done.

\section{RESULTS AND DATA ANALYSIS}

Total number of Patients- 100

Male- $(53 \%)$

Female- (47\%)

Mean Age of Patients $=54$ years, Mean Age of Newly Diagnosed Diabetes $=50$ years.

Maximum patients with diabetes are between $41-60$ years.

\begin{tabular}{|c|c|c|c|}
\hline Age (Years) & Male & Female & Total N=100 \\
\hline $34-40$ & 3 & 2 & 5 \\
\hline $41-50$ & 15 & 16 & 31 \\
\hline $51-60$ & 22 & 17 & 39 \\
\hline $61-70$ & 11 & 10 & 21 \\
\hline$>70$ & 2 & 2 & 4 \\
\hline \multicolumn{4}{|c|}{ Table 1. Age and Sex Distribution } \\
\hline
\end{tabular}

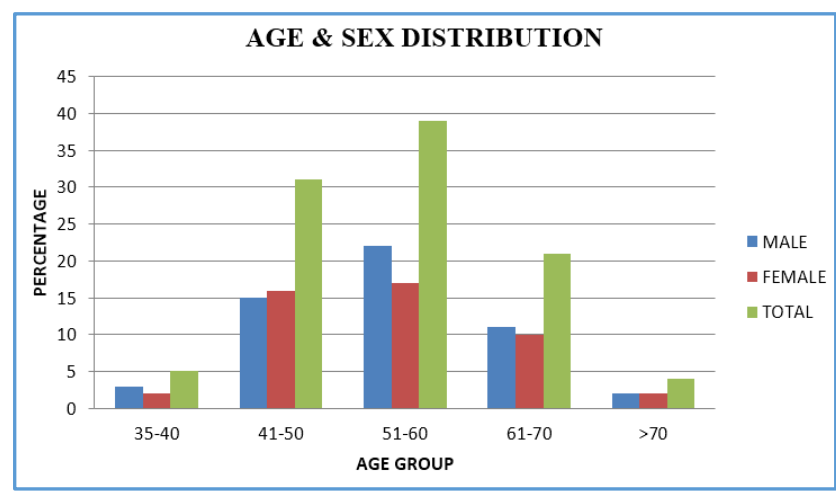

$70 \%$ of Patients have duration of Diabetes of $<5$ years.

\begin{tabular}{|c|c|c|c|}
\hline Duration of DM & Male & Female & Total \\
\hline New Case & 19 & 15 & 34 \\
\hline$<5$ & 19 & 17 & 36 \\
\hline $5-10$ & 10 & 10 & 20 \\
\hline$>10$ & 5 & 5 & 10 \\
\hline \multicolumn{3}{|c|}{ Table 2. Duration of DM } \\
\hline
\end{tabular}

Positive Family History of DM in 31\% of Patients.

\begin{tabular}{|c|c|}
\hline Family History of DM & Total (n=100) \\
\hline Positive & $31 \%$ \\
\hline Negative & $69 \%$ \\
\hline \multicolumn{2}{|c|}{ Table 3. Positive Family History with DM } \\
\hline
\end{tabular}

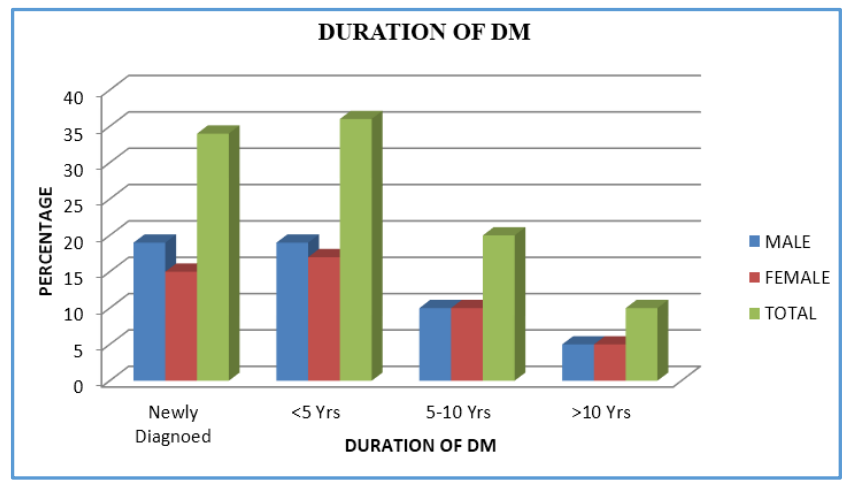

\section{Data on Risk Factors}

Total Number of Patients with Hypertension in Diabetes is $72 \%$.

Newly diagnosed Patients with Hypertension are 65\%.

\begin{tabular}{|c|c|c|c|c|c|}
\hline Category & $\begin{array}{c}\text { Newly } \\
\text { Diagnosed } \\
(\mathrm{n}=34)\end{array}$ & $\begin{array}{l}<5 \text { yrs. } \\
(n=36)\end{array}$ & $\begin{array}{c}5-10 \\
\text { yrs. } \\
(n=20)\end{array}$ & $\begin{array}{l}10 \text { yrs. } \\
(n=10)\end{array}$ & $\begin{array}{c}\text { Total } \\
(n=100)\end{array}$ \\
\hline $\begin{array}{c}\text { Pre-HT } \\
120-139 \\
80-89 \\
\end{array}$ & 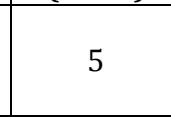 & 12 & 3 & 2 & 22 \\
\hline $\begin{array}{c}\text { Stage } 1 \\
140-159 \\
90-99 \\
\end{array}$ & 11 & 14 & 10 & 4 & 39 \\
\hline \begin{tabular}{|c|} 
Stage 2 \\
$160 / 100$ \\
and Above
\end{tabular} & 6 & 2 & 1 & 2 & 11 \\
\hline Total & $22(65 \%)$ & \begin{tabular}{|c|}
28 \\
$(78 \%)$
\end{tabular} & $\begin{array}{c}14 \\
(70 \%)\end{array}$ & $8(80 \%)$ & $72 \%$ \\
\hline \multicolumn{6}{|c|}{ Table 4. Category of Hypertension and DM } \\
\hline
\end{tabular}

$51 \%$ of Newly Diagnosed Patients are Obese/ Overweight.

\begin{tabular}{|c|c|c|c|c|c|}
\hline $\begin{array}{c}\text { Obesity } \\
\text { BMI }\end{array}$ & $\begin{array}{c}\text { Newly } \\
\text { Diagnosed } \\
(\mathbf{n = 3 4 )}\end{array}$ & $\begin{array}{c}<\mathbf{5} \text { yrs. } \\
(\mathbf{n}=\mathbf{3 6})\end{array}$ & $\begin{array}{c}\mathbf{5 - 1 0} \text { yrs. } \\
(\mathbf{n}=\mathbf{2 0})\end{array}$ & $\begin{array}{c}\mathbf{1 0} \text { yrs. } \\
(\mathbf{n = 1 0})\end{array}$ & $\begin{array}{c}\text { Total } \\
(\mathbf{n}=\mathbf{1 0 0})\end{array}$ \\
\hline $\begin{array}{c}\text { Overweight } \\
25-30\end{array}$ & 14 & 18 & 9 & 5 & $46(46 \%)$ \\
\hline Obese $>30$ & 3 & 3 & 3 & 2 & $11(11 \%)$ \\
\hline Total & $\mathbf{1 7}(\mathbf{5 1 \% )}$ & $\mathbf{2 1 ( 5 9 \% )}$ & $\mathbf{1 2 ( 6 0 \% )}$ & $\mathbf{7 ( 6 9 \% )}$ & $\mathbf{5 7}(57 \%)$ \\
\hline \multicolumn{5}{|c|}{ Table 5. Obesity and Duration of DM } \\
\hline
\end{tabular}

$69 \%$ of patients have abdominal obesity based on waist circumference.

\begin{tabular}{|c|c|}
\hline Sex & Total \\
\hline Male $\mathrm{n}=53$ & $34(65 \%)$ \\
\hline Female $\mathrm{n}=47$ & $34(72 \%)$ \\
\hline Total $\mathbf{n}=\mathbf{1 0 0}$ & $\mathbf{6 8}(\mathbf{6 8 \% )}$ \\
\hline Table 6. DM and Abdominal Obesity \\
\hline
\end{tabular}

$21(61 \%)$ of newly diagnosed patients have hypercholesterolaemia.

\begin{tabular}{|c|c|c|c|c|}
\hline $\begin{array}{c}\text { Total } \\
\text { Cholesterol } \\
\text { mg/dL }\end{array}$ & $\begin{array}{c}\text { Newly } \\
\text { Diagnosed } \\
(\mathbf{n = 3 4 )}\end{array}$ & $\begin{array}{c}<5 \\
\text { Years } \\
(\mathbf{n}=\mathbf{3 6})\end{array}$ & $\begin{array}{c}\mathbf{5 - 1 0} \\
\text { Years } \\
(\mathbf{n}=\mathbf{2 0})\end{array}$ & $\begin{array}{c}\mathbf{1 0} \\
\text { Years } \\
(\mathbf{n = 1 0})\end{array}$ \\
\hline $200-239$ & 8 & 14 & 8 & 5 \\
\hline $\begin{array}{c}240 \text { and } \\
\text { Above }\end{array}$ & 13 & 14 & 9 & 3 \\
\hline Total & $\mathbf{2 1 ( 6 1 \% )}$ & $\mathbf{2 8}(\mathbf{7 9 \% )}$ & $\mathbf{1 7}(\mathbf{8 3 \% )}$ & $\mathbf{8 ( 8 4 \% )}$ \\
\hline \multicolumn{4}{|c}{ Table 7. DM and Hypercholesterolaemia } \\
\hline
\end{tabular}


Most common risk factor with DM is hypercholesterolaemia- 91 (74\%).

Next common risk factor is hypertension- 76 (72\%).

\begin{tabular}{|c|c|c|c|}
\hline Risk Factor & Male & Female & Total \\
\hline Hypertension & 42 & 30 & $72(72 \%)$ \\
\hline Obesity & 30 & 27 & $57(57 \%)$ \\
\hline Smoking & 24 & NIL & $24(24 \%)$ \\
\hline Hypercholesterolaemia & 38 & 36 & $74(74 \%)$ \\
\hline \multicolumn{4}{|c|}{ Table 8. Risk Factor and DM } \\
\hline
\end{tabular}

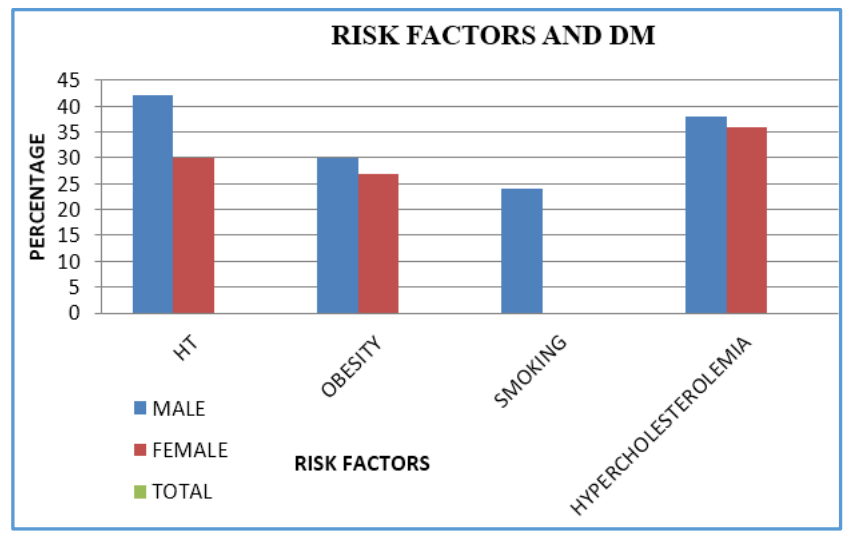

\section{Data on Microvascular Complications}

Retinopathy is the most common microvascular complication. Retinopathy (34\%), Nephropathy (31\%) and Neuropathy (20\%) present at the time of DM.

\begin{tabular}{|c|c|c|c|c|c|}
\hline $\begin{array}{c}\text { Microvascular } \\
\text { Complication }\end{array}$ & $\begin{array}{c}\text { Newly } \\
\text { Diagnosed } \\
(\mathbf{n = 3 4 )}\end{array}$ & $\begin{array}{c}<\mathbf{5} \\
\text { Years } \\
(\mathbf{n = 3 6})\end{array}$ & $\begin{array}{c}\mathbf{5 - 1 0} \\
\text { Years } \\
(\mathbf{n = 2 0})\end{array}$ & $\begin{array}{c}\mathbf{1 0} \\
\text { Years } \\
(\mathbf{n = 1 0})\end{array}$ & $\begin{array}{c}\text { Total } \\
(\mathbf{n = 1 0 0})\end{array}$ \\
\hline Retinopathy & $12(34 \%)$ & $\begin{array}{c}10 \\
(27 \%)\end{array}$ & $\begin{array}{c}7 \\
(37 \%)\end{array}$ & $\begin{array}{c}5 \\
(50 \%)\end{array}$ & $\begin{array}{c}34 \\
(34 \%)\end{array}$ \\
\hline Neuropathy & $8(24 \%)$ & $\begin{array}{c}6 \\
(18 \%)\end{array}$ & $\begin{array}{c}4 \\
(20 \%)\end{array}$ & $\begin{array}{c}2 \\
(20 \%)\end{array}$ & $\begin{array}{c}20 \\
(20 \%)\end{array}$ \\
\hline Nephropathy & $8(24 \%)$ & $\begin{array}{c}10 \\
(27 \%)\end{array}$ & $\begin{array}{c}9 \\
(46 \%)\end{array}$ & $\begin{array}{c}4 \\
(40 \%)\end{array}$ & $31(31 \%)$ \\
\hline
\end{tabular}

Table 9. Microvascular Complication and Duration on DM

Non-proliferative Retinopathy is the most common complication in Retinopathy.

\begin{tabular}{|c|c|}
\hline Types & Total (n=34) \\
\hline Non-proliferative retinopathy & $29(88 \%)$ \\
\hline Proliferative retinopathy & $3(9 \%)$ \\
\hline Maculopathy & $2(6 \%)$ \\
\hline \multicolumn{2}{|c|}{ Table 10. Types of Diabetic Retinopathy } \\
\hline
\end{tabular}

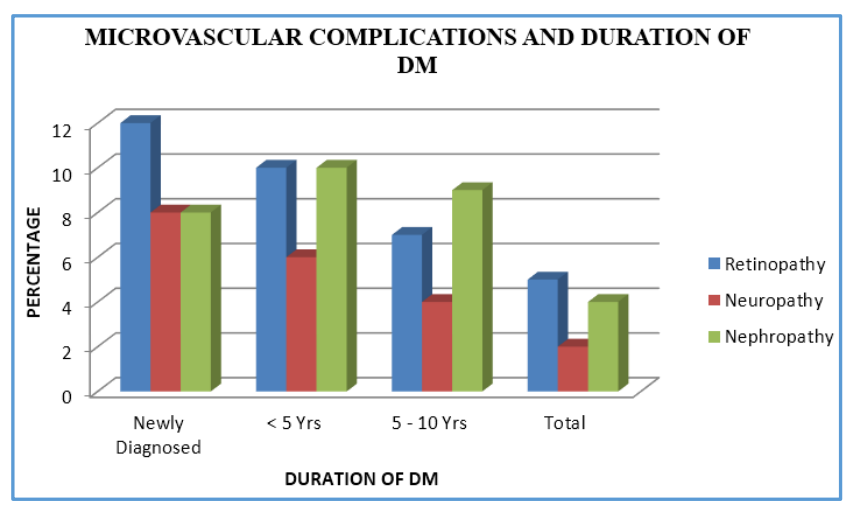

$43 \%$ of DM patients with CKD are in stage 2. No patients with DM were found in stages 4 and 5 in this study.

\begin{tabular}{|c|c|c|}
\hline GFR & Stages of CKD & Total n=32 \\
\hline $90-120$ & Stage 1 & $7(23 \%)$ \\
\hline $60-89$ & Stage 2 & $14(43 \%)$ \\
\hline $30-59$ & Stage 3 & $11(34 \%)$ \\
\hline$<30$ & Stage $4 \$ 5$ & Nil \\
\hline \multicolumn{2}{|c|}{ Table 11. Stages of CKD in Diabetes } \\
\hline
\end{tabular}

$11 \%$ of DM patients have renal failure.

\begin{tabular}{|c|c|}
\hline Serum Creatinine & Total $\mathbf{N = 1 0 0}$ \\
\hline$<1.5 \mathrm{mg} / \mathrm{dL}$ & $89(89 \%)$ \\
\hline $1.5-3 \mathrm{mg} / \mathrm{dL}$ & $11(11 \%)$ \\
\hline \multicolumn{2}{|c|}{ Table 12. Renal Failure in DM } \\
\hline
\end{tabular}

Data on Macrovascular Complication.

\begin{tabular}{|c|c|}
\hline Duration & Total N=36 \\
\hline Newly Diagnosed & $10(28 \%)$ \\
\hline$<5$ years & $15(42 \%)$ \\
\hline $5-10$ years & $6(17 \%)$ \\
\hline$>10$ years & $5(14 \%)$ \\
\hline \multicolumn{2}{|c|}{ Table 13. CAD and DM } \\
\hline
\end{tabular}

$47 \%$ of patients with CAD are asymptomatic.

\begin{tabular}{|c|c|}
\hline Manifestation & Total \\
\hline Symptomatic & $19(53 \%)$ \\
\hline Asymptomatic & $17(47 \%)$ \\
\hline \multicolumn{2}{|c|}{ Table 14. Manifestation of CAD } \\
\hline
\end{tabular}

The most common macrovascular complication is CAD (36\%).

\begin{tabular}{|c|c|}
\hline Complication & Total N= 100 \\
\hline CAD & $36(36 \%)$ \\
\hline Peripheral Vasc. Disease & $6(6 \%)$ \\
\hline CVA & $10(10 \%)$ \\
\hline Table 15. Macrovascular Complications and DM \\
\hline
\end{tabular}

\section{DISCUSSION}

The total no. of patients analysed were 100, out of which $53 \%$ were male and $47 \%$ were female patients. The mean age of patients found in the study was 54 yrs. These findings correlate with studies done by Raheja et al, ${ }^{1}$ which showed the mean age of 53.3 years and another study by National Rural Diabetes Survey of 1989 - 91, which showed mean age of subjects with diabetes with 52.3 yrs. $^{2}$ In the present study, the mean age of newly diagnosed diabetes is found to be 50 yrs.

The prevalence of diabetes increases with age. In elderly patients, the study is $39 \%$ with maximum cases in elderly being 51 - 60 years' age group. This finding correlate with studies done by Ahuja MMS. ${ }^{3}$ Epidemiological studies of DM in India showed prevalence of diabetes in elderly patients (age > 60 yrs.) in urban population as $23.4 \%$ and maximum prevalence was in age group of 61 - 69 years.

Out of 100 patients, $31 \%$ cases had positive family history of diabetes. Many Indian studies show strong association of positive family history in DM type 2 . These findings correlate with study of Shah et al (1999),4 which showed positive family history of $24.9 \%$ and Ramachandran et al (1999) 5 
which showed strong correlation of positive family history with DM type 2.

\section{Risk Factors/ Hypertension}

The prevalence of hypertension in diabetes in the present study is $72 \%$. Out of the total 72 patients with hypertension, $65 \%$ patients had hypertension at the time of diagnosis. CDC's National Diabetes Surveillance System 2005, USA ${ }^{6}$ shows $62.5 \%$ of patients have hypertension in diabetes. Among the stages of hypertension according to JNC VII report, maximum patients $53 \%$ were in Stage 1. Various Indian studies show prevalence of hypertension in DM to be around $50 \%-80 \%$.

\section{Obesity}

This study shows that $57 \%$ patients were overweight and obese according to BMI. But when waist circumference was taken, $68 \%$ patients had abdominal obesity. This correlates with a study done by Channaraya et al (2002), ${ }^{7}$ which showed truncal obesity based on waist circumference was 69\%. Many of Indian studies showed strong correlation between obesity and DM type 2.

\section{Smoking}

$20 \%$ of the patients in the present study were smokers and all of them were males. A study by SV Madhu et al (2002) ${ }^{8}$ showed smokers to be $15 \%$ and an International study by CDC- National Diabetes Surveillance System, 2005, USA ${ }^{6}$ shows smokers at $17.7 \%$ among diabetic patients.

\section{Hypercholesterolaemia}

Out of 100 patients, $74 \%$ patients had hypercholesterolaemia. $61 \%$ patients had hypercholesterolaemia at the time of diagnosis. This study correlates with a study done by CDCNational Diabetes Surveillance System, 2005, USA, 6 which showed the hypercholesterolaemia at $60 \%$ and a study done by S Shafiq et al (2001). ${ }^{9}$

The most common risk factor in diabetes is hypercholesterolaemia, which is $74 \%$. Next common risk factor is hypertension. All these risk factors play a significant role in the pathogenesis of Macrovascular complications. The risk factor- Hypertension - 65\%, Obesity - 51\% and Hypercholesterolaemia - $61 \%$ were present at the time of diagnosis.

\section{Microvascular Complications}

Diabetic Retinopathy $34 \%$ is the most common microvascular complication. Out of the patients with Retinopathy, $88 \%$ had non-proliferative Retinopathy. The prevalence of Retinopathy increases according to the duration of diabetes. This study correlates with the study done by G Premalatha and V Mohan et al (2002)10 in Urban South Indian Population, which showed that Retinopathy was $34.1 \%$ and M Ranka et al (2004) ${ }^{11}$ found it to be $28.9 \%$ in a North Indian study.

CKD in Diabetes was seen in $32 \%$ of patients in the study. Out of the patients with CKD, maximum patients i.e. $42 \%$ were in Stage 2; $18 \%$ of them had Proteinuria. Microalbuminuria was not done in this study. The finding however correlates with the study done by Ramachandra et al (1999), 5 which showed prevalence of Proteinuria at $19.7 \%$.

Diabetic Neuropathy was prevalent in $20 \%$ of patients. This finding however correlates with the study done by $G$
Premalatha and V Mohan et al (2002), ${ }^{10}$ which had 19.1\% patients with Neuropathy.

A significant finding in the study of Retinopathy 34\%, Neuropathy $20 \%$ and Nephropathy $31 \%$ were present at the time of diagnosis.

\section{Macrovascular Complications}

Coronary Artery Disease- $36 \%$ is the most common Macrovascular complication in the study. $47 \%$ of patients with CAD were asymptomatic in the study. $72 \%$ of patients with CAD had duration of DM of $<5$ years.

Peripheral Vascular Disease was present in $6 \%$ of patients in the study. This correlates with the study by $\mathrm{G}$ Premalatha and V Mohan et al (2002), ${ }^{10}$ which showed 4\%.

Cerebrovascular disease was found in $10 \%$ of patients in the study. This correlates with the International Study CDCNational Diabetes Surveillance System, 2005, USA, 6 which showed 9\% prevalence of stroke in DM type 2.

\section{CONCLUSION}

1. In this study $53 \%$ of patients were males and $47 \%$ were females, all of them being above 35 years of age. The mean age of the patients was 54 years.

2. The highest number of patients with diabetes was in the age group of 51 - 60 years.

3. $70 \%$ of patients had duration of diabetes $<5$ years.

4. Hypertension was found in $72 \%$ of patients.

5. Obesity was found in $57 \%$ of patients.

6. $45 \%$ of the males were smokers.

7. Hypercholesterolaemia was found in $74 \%$ of patients.

8. The highest risk factor was Hypercholesterolaemia followed by Hypertension.

9. Retinopathy was found in $34 \%$ of patients.

10. Neuropathy was found in $20 \%$ of the patients.

11. Nephropathy was found in $31 \%$ of the DM patients.

12. Newly diagnosed DM patients presented with Retinopathy in 34\%, Neuropathy in $24 \%$ and Nephropathy in $24 \%$.

13. Coronary artery disease was found in $36 \%$ of patients.

14. Peripheral Vascular Disease was found in $6 \%$ of patients.

15. Cerebrovascular disease was found in $10 \%$ of patients.

\section{REFERENCES}

[1] Raheja BS, Kapur A, Bhoraskar A, et al. Diab Care Asia-India study: diabetes care in India--current status. The Journal of the Association of Physicians of India 2001;49:717-22.

[2] Rao PV, Shyam C. Reflectometry in epidemiological studies for diabetes mellitus - Indian J Endocrinol Metab 1997;1:16-8.

[3] Ahuja MMS. Diabetes mellitus in India in the context of social change. Bombay, India: Health Care Communications 1996.

[4] Shah SK, Saikia M, Burman NN, et al. High prevalence of type 2 diabetes in urban population in north eastern India. Int J Diabetes Dev Countries 1999;19:144-7.

[5] Ramachandran A, Snehalatha C, Satyavani K, et al. Prevalence of vascular complications and their risk factors in type 2 diabetes. The Journal of the Association of Physicians of India 1999;47(12): 1152-6. 
[6] National estimates on diabetes - CDC, HIS, US Renal Data System of the NIH: census bureau. 2005.

[7] Channayraya. Study of silent myocardial ischaemia and microalbuminuria in asymptomatic subjects with NIDDM. JAPI 2002.

[8] Madhu SV, Singh NR. Prevalence of cardiovascular risk factor at presentation with Type 2 DM. JAPI 2002.

[9] Shafiq J, Ahmed. Profile of dyslipidaemia in type 2 diabetic subject - a hospital based study. JAPI 2001.
[10] Premalatha G, Rema M. Diabetes and related complications in urban South Indians: type 2 Diabetes - the Indian Scenario 2025? - $1^{\text {st }}$ edn. Publ. Dr M. Jayaram 2002:185-9.

[11] Ranka M, Katyal V. Prevalence of micro and macro vascular complications and their risk factors on DM type 2 - a Study from North India - Int J Diab Dev Countries 2004;24:11-6. 